\title{
Unusual Foreign Objects in the Teeth - A Case Report
}

\author{
David Ditto Sharmin*, Sravanthi Sistla and Rajasekar Gunasekaran \\ Meenakshi Ammal Dental College, Chennai, India
}

Received: July 29, 2017; Accepted: August 22, 2017; Published: September 25, 2017

*Corresponding author: David Ditto Sharmin, Reader, Meenakshi Ammal Dental College, Chennai, India, E-mail: dr.dittosharmin@gmail.com

\begin{abstract}
Discovering foreign objects in the teeth is often accidentally. A detailed case history, including history of habitual placement of the objects, clinical and radiographic examinations are necessary to come to a conclusion about the nature, size, location of the foreign body and the difficulty involved in its retrieval. Sometimes the foreign objects fracture inside the tooth while exploration by the parent or the child. These foreign objects may act as a potential source of infection and may later lead to complications. This paper discuss a cases of different foreign object impaction in the teeth along with the management of the cases that have been reported to the Department of Pediatric and Preventive Dentistry, Meenakshi Ammal Dental College and Hospital, Chennai, India.
\end{abstract}

Key Words :Foreign objects; Source of infection; Fracture; Habitual placement;

\section{Introduction}

Foreign objects that are found in pulp chamber or root canal of a tooth are often diagnosed accidentally on examination. It may be associated with pain, swelling and recurrent abscess. It is common for children as they have the habit of placing these objects in the mouth. Children with fractured tooth may use foreign bodies like stapler pins, all kinds of pins, toothpicks, etc., to explore the tooth.

These objects eventually can get lodged in the pulp chamber or root canal of the tooth and cause a potential focus of infection. Sometimes, the tooth remains asymptomatic but other times it manifests as pain, tenderness, swellings etc. Presence of these objects prevents thorough instrumentation of root canal system. So, their removal is necessary to renegotiate the canal and complete the endodontic treatment successfully. The objects can be retrieved with some ease if they are located within the pulp canal. But once the object has been pushed apically, their retrieval becomes complicated and surgery becomes unavoidable [1].

\section{Case Report}

A 12 year old female patient reported to the Department of Pediatric and Preventive Dentistry with a complaint of pain in the upper right back tooth region since 2 months. The pain was continuous in nature and was of dull-aching type. The past medical history was taken and the patient confirmed no previous history of hospitalization, no allergy to any medication and absence of any cardiovascular or respiratory disorders and/or other systemic conditions.

The patient revealed a history of using stapler pins, microtip pencil leads and stalking pencil to remove the food lodged in the carious teeth. Doing so eventually reduced the pain for the patient. On clinical examination, the carious teeth were noticed in relation to 54 and 55 and presence or plaque and calculus.

Upon radiographic examination, the intraoral periapical radiograph revealed the presence of radiopaque foreign bodies in relation to 54 and 55. Oral prophylaxis was done before the planned extraction was carried out. Extraction of the teeth was done after the retrieval of the foreign bodies. Upon retrieval, stapler pin, micro-tip pencil lead and a stalking pencil lead was removed from the region of 54 and 55.
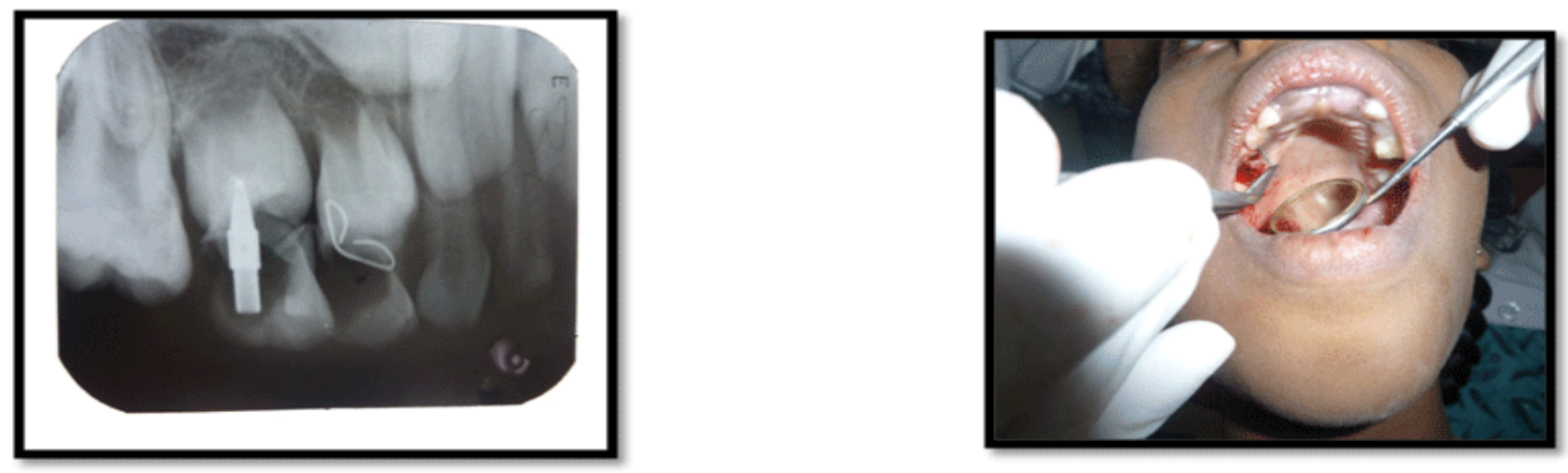


\section{Discussion}

The discovery of foreign bodies in the teeth is a special situation, which is often diagnosed accidentally. Root canals or pulp chamber of a tooth can be blocked by the presence of broken instruments, canal obturation materials, and in some cases, by foreign objects inserted by the patient himself. It can occur in patients undergoing root canal treatment in which canals have been left open for drainage or after trauma. The presence of foreign body prevents thorough instrumentation of root canal system and adversely affects the outcome of successful endodontic treatment.

Various foreign objects were reported to be lodged in the root canals and the pulp chamber, which ranged from pencil leads [2], metal screws [3], to beads [4], darning needles [5] and stapler pins [6]. Similarly Grossman had also reported the retrieval of ink pencil tips, tooth picks, adsorbent points and even tomato seeds from the root canals of anterior teeth [7]. Toida has reported a plastic chopstick embedded in an unerupted supernumerary tooth in the premaxillary region of a 12-year-old Japanese boy [8]. Zillich and Pickens and Turner have cited cases where hat pins and dressmaker pins that were used to remove the food plugs from the root canals of maxillary and mandibular incisors undergoing endodontic treatment had eventually fractured inside the root canals of these teeth [9] \& [10].

Radiographs can be of diagnostic significance especially if the foreign body is radio-opaque. McAuliffe summarized that various radiographic methods can be used to localize a radio-opaque foreign object [6]. Views such as Parallax views, Occlusal views and Triangulation techniques can be of use to identify and localize the object. Triangulation uses two views right angle views to one another but here the interpretation is difficult because of the superimposition of the other incisor teeth over the root.

For retrieval of foreign objects lying in the pulp chamber or canal using ultrasonic instruments [11], the Masserann kit [12], modified Castroviejo needle holders have been used [14]. Ethylenediaminetetraacetic acid has been suggested as a useful aid in lubricating the canal when attempting to remove the foreign object. The Stieglitz forceps have been described for use of removal of silver points from the root canal.

McCullock stated that access to the foreign object is improved by removal of small amount of tooth structure [14]. Walvekar et al suggested that if the foreign object is snugly bound in the canal, the object may have to be loosened first and then be removed with minimal damage to internal tooth structure [15].

\section{Conclusion}

As Pediatric Dentists we see cases of foreign body inclusions in the teeth of children due to several reasons. Parents and children do insert foreign objects inside the tooth for exploration purposes which eventually may get fractured and cause further complications. Hence it is extremely essential to educate the parents and children to avoid using such objects and to prevent such mishaps from occurring.

\section{References}

1. Roig-Greene JL. The retrieval of foreign objects from root canals: A simple aid. J Endod. 1983;9(9):394-397.

2. Hall JB. Endodontics - Patient performed. ASDC J Dent Child, 1969;36(3):213-216

3. Prabhakar AR, Basappa N, Raju OS. Foreign body in a mandibular permanent molar: A case report. J Indian Soc Pedod Prev Dent. 1998;16(14):120-121.

4. Subba Reddy VV, Mehta DS. Beads. Oral Surg Oral Med Oral Pathol. 1990;69(6):769770.

5. Nernst H. Foreign body in the root canal. Quintessenz. 1972;23(8):26

6. Mcauliffe N, Drage NA, Hunter B. Staple diet: A foreign body in a tooth. Int J Paediatr Dent. 2005;15(6):468-471

7. Grossman JL, Heaton JF. Endodontic case reports. Dent Clin North Am. 1974;18(2):509527.

8. Toida M, Ichihara H, Okutomi T, Nakamura K, Ishimaru JI. An unusual foreign body in an unerupted supernumerary tooth. Br Dent J. 1992;173(10):345-346.

9. Zillich RM, Pickens TN. Patient-included blockage of the root canal: Report of a case. Oral Surg Oral Med Oral Pathol. 1982;54(6):689-690.

10.Turner CH. An unusual foreign body. Oral Surg Oral Med Oral Pathol. 1983;56(2):226.

11.Meidinger DL, Kabes BJ. Foreign object removal utilizing the cavi-endo ultrasonic instrument. J Endod. 1985;11(7):301-304.

12.Williams VD, Bjourndal AM. The Masseran technique for the removal of fractured posts in endodontically treated teeth. J Prosthet Dent. 1983;49(1):46-48.

13.Fros UG, Berg JO. A method for the removal of broken endodontic instruments from the root canals. J Endod. 1983;9(4):156-159.

14.McCullock AJ. The removal of restorations and foreign objects from root canals. Quintessence Int. 1993;24(4):245-249.

15.Walvekar SV, Al-Duwari Y, Al-Kandri AM, Al-Quoud OA. Unusual foreign objects in the root canal. J Endod. 1995;21(10):526-527. 